Anne M C Webb, MRCOG, MFFP

Consultant in Family Planning and Reproductive Health Care, Abacus Clinics for Contraception and Reproductive Health, 40-46 Dale Street, Liverpool L2 5SF, UK. E-mail: anne.webb@pct.northliverpool.nhs.uk

\section{References}

1 von Hertzen H, Piaggio G, Ding J, et al. Low dose mifepristone and two regimes of levonorgestrel for emergency contraception: a WHO multicentre randomised trial. Lancet 2002; 306: 1803-1810.

2 Task Force on Postovulatory Methods of Fertility Regulation. Randomised controlled trial of levonorgestrel versus the Yuzpe regimen of combined oral contraceptives for emergency contraception. Lancet 1998; 352: 428-433.

3 Ellertson C, Evans M, Ferden S, et al. Extending the time limit for starting Yuzpe regimen of emergency contraception to 120 hours.
Obstet Gynecol 2003; 101: 1168-1171.

4 Harrison-Woolrych M, Woolley J. Progestogen-only emergency contraception and ectopic pregnancy. J Fam Plann Reprod Health Care 2003; 29(1): 5-6.

5 Trussell J, Hedley A, Raymond E. Ectopic pregnancy following use of progestin-only ECPs (Letter). J Fam Plan Reprod Health Care 2003; 29(4): 249.

6 Department of Health. Judicial Review of Emergency Contraception. London, UK: Department of Health, 2002.

7 Kettle H, Cay S, Brown A, et al. Screening for Chlamydia trachomatis infection is indicated for women under 30 using emergency contraception. Contraception 2002; 66: 251-253.

8 Glasier A, Baird D. The effects of self-administered emergency contraception. N Engl J Med 1998; 339: 1-4

9 Kasliwal A, Whitmore J. Advance provision of emergency contraception: is it feasible? Oral presentation at the Faculty of Family Planning and Reproductive Health AGM and Annual Symposium, Manchester, UK, May 2003.

\title{
Off-licence prescribing in contraception
}

Did you realise that suggesting a tricycle pill regimen to a woman suffering from dysmenorrhoea, or the use of the Mirena ${ }^{\circledR}$ intrauterine system as part of hormone replacement therapy (HRT), is outside the product licences for these particular medicines? In everyday practice we use licensed products in an unlicensed way but give little thought to the consequences of our actions. What guidance is in place to provide protection for the health professional? How do we ensure safe prescribing?

It is unlikely that we will prescribe an unlicensed medicine in sexual and reproductive health unless we are involved in research. To ensure that medicines are safe and effective, the manufacture, sale or supply of medicinal products is controlled by national and European Economic Community (EEC) (now European Community, EC) legislation. ${ }^{1,2}$ Therefore all medicines available in the UK are issued with a Marketing Authorisation (commonly known as a product licence).

If licensed medicines are being used in an 'off-licence' situation the manufacturer cannot generally be held liable for any problems that may arise from such use. Legal liability is therefore likely to rest more heavily with the prescriber and their employer, normally a National Health Service (NHS) Trust. ${ }^{3}$ There are many occasions in the field of contraception when licensed medicines are justifiably prescribed for unlicensed indications or to groups of patients not covered by the Marketing Authorisation (Table 1). Very often the off-licence use of a medicine for another therapeutic indication becomes standard practice and it is only when Patient Group Directions (PGDs) are being developed that this comes to light. An example of this is the use of a hormonal contraceptive to treat dysmenorrhoea rather than for birth control.

Many nurses and pharmacists now supply and administer medicines under guidance of a PGD. These are written documents that cover the supply and/or administration of prescription-only medicine by certain classes of health professionals to benefit patient care without compromising safety. PGDs have to be authorised by a Primary Care Trust, NHS Trust or Health Authority and be signed by a doctor or dentist, and a pharmacist who should be involved in their development, in order to be valid. ${ }^{4}$ Nurse prescribers are able to prescribe a limited number of medicines. However, nurses can only issue/prescribe licensed medicines for licensed indications.

A number of recommendations for prescribing drugs off-licence have been suggested by the Newcastle Drug and Therapeutics Committee. ${ }^{5}$ These recommendations are worth disseminating more widely to ensure safe prescribing.
1. A licensed medicine should not be used outside the terms of its product licence unless its use can be justified; usually one or more of the following scenarios apply:

- The particular unlicensed use is well established, e.g. endorsed by a responsible body of professional opinion such as the Faculty of Family Planning and Reproductive Health Care.

- No product that is licensed for the purpose is available.

- The unlicensed use of a medicine is likely to offer a significant clinical (medical or pharmaceutical) advantage compared with a product licensed for the purpose.

2. Depending on the likely frequency of use and the possible level of risk associated with the unlicensed use of a medicine, the clinician wishing to prescribe the medicine should consider:

- Discussing the matter with a senior colleague, e.g. in difficult clinical circumstances where treatment options are limited and a second opinion is warranted.

- Obtaining clearance for its regular use through the appropriate local drug and therapeutics committee.

- Discussing the unlicensed use and possible risks involved with the patient and/or relative(s), and in some (high-risk) cases obtain their informed consent. This should be recorded in the clinical records together with the points discussed.

Table 1 Common examples of using licensed products in an unlicensed way

1 Use of the levonorgestrel intrauterine system as the progestogen component of hormone replacement therapy.

2 Use of emergency hormonal contraception beyond 72 hours and up to 120 hours after the earliest time of unprotected sexual intercourse.

3 Use of emergency hormonal contraception more than once in a cycle.

4 Use of 'add-back' oestrogen together with Depo-Provera ${ }^{\circledR}$ to treat hypo-oestrogenic symptoms or management of bleeding problems.

5 Use of Depo-Provera or a combined oral contraceptive (COC) to alleviate menstrual cycle problems such as Mittelschmertz pain and dysmenorrhoea.

6 Advising the use of more than one pill per day when enzymeinducers are being used with a COC; or two progestogen-only pills daily in the obese young woman.

7 Omission or shortening of the pill-free interval when taking a COC.

8 Use of copper intrauterine devices for longer than their licensed time, particularly after the age of 40 years. 
- Keeping a separate record of the patient's details, which enables quick identification if an adverse event is reported. In Newcastle the clinician documents and patient and drug details are kept in a designated file.

Failure to inform the patient adequately may cause problems should there be an adverse event that results in litigation, for example, if a patient became pregnant while using a progestogen-only pill both for contraception and as part of HRT to help vasomotor symptoms.

3. When a medicine is prescribed to a patient outside the terms of its product licence this should be explained to the individual in a way that does not cause alarm. Consideration should be given to advising the patient (and/or his/her parent/carer where appropriate) that some of the details in a manufacturer's patient information leaflet may not be appropriate. The use of the medication should also be documented in the patient's notes. Ensure good practice including follow-up, to comply with professional indemnity requirements. This will often mean the doctor needs to provide dedicated written material to supplement the manufacturer's leaflet.

4. Where a clinician wishes to recommend the use of a medicine for an unlicensed purpose to another doctor, he/she should point out that the product is not licensed for that purpose and mention any known or perceived problems/risks associated with its use.

5. Where a hospital or clinic doctor wishes the continued prescribing of medicines outside their product licence by a general practitioner (GP), this should normally only be done with the agreement of the GP. The GP should also be informed of relevant information that has been given to the patient.

Many drug and therapeutics committees are advising the development of written shared care contracts between the hospital/clinic specialist and the GP. These should be concise and, as far as practicable, evidence-based. Shared care arrangements should not be implemented until treatment is stabilised and agreement has been obtained from the GP. Information given to the GP should include:

- an explanation as to why the treatment has been chosen;

- details regarding dosage regimen and likely duration of treatment;

- patient-specific instructions, e.g. for monitoring and adjusting dosage within an agreed range and

- details of any monitoring and other aspects of care that will continue to be provided by the hospital/clinic.

New medicines (as indicated by the symbol $\boldsymbol{\nabla}$ in the British National Formulary, etc.) should not normally be recommended to GPs for use outside licensed indications.

6. Serious or unusual adverse reactions that occur following the unlicensed use of a medicine should be reported to the Committee on Safety of Medicines (CSM) using the Yellow Card scheme.

If this guidance is followed when prescribing 'offlicence', best practice will be achieved and there will be little fear of litigation. The user will also benefit from a wider range of treatment options. We all know that changing/increasing the indications for licensed medicines can take time and very often the manufacturer will not seek these unless it is economically viable for them to do so. When in doubt it is always worth asking your local pharmacy advisor for help and if they do not know the answer they often know a person who does.
Statements on funding and competing interests Funding. None identified.

Competing interests. Diana Mansour has received financial support for lecturing, attending conferences and undertaking research for a number of pharmaceutical companies. She is also a member of advisory boards for a number of companies.

\section{Diana Mansour, FRCOG, MFFP}

Consultant in Community Gynaecology and Head of Service, Contraception and Sexual Health, Newcastle General Hospital, Westgate Road, Newcastle-upon-Tyne NE4 6BE, UK. E-mail: diana.mansour@newcastlepct.nhs.uk

Glyn Trueman, MSc, MRpharmS

Formulary Pharmacist, The Freeman Hospital, Newcastleupon-Tyne, $U K$

References

1. Council Directive 65/65/EEC of 26 January 1965 on the approximation of provisions laid down by law, regulation or administrative action relating to medicinal products.

2 SI No. 3144/1994, The Medicines for Human Use (Marketing Authorisations, etc.) Regulations 1994.

3 Prescribing unlicensed drugs or using drugs for unlicensed indications. Drug Ther Bull 1992; 30: 97-99.

4 Health Service Circular (HSC 2000/026) on Patient Group Directions (England only).

5 Newcastle Drug and Therapeutics Committee. Unlicensed uses of licensed medicines, 2002.

\section{herpes simplex can be more than a physical problem}

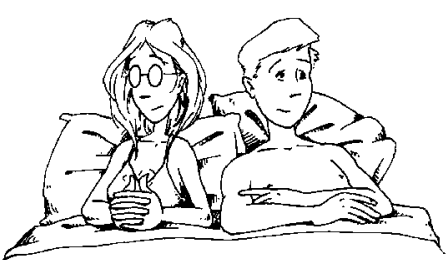

The Herpes Viruses Association helpline supplies information to patients and medical practitioners. Helpline volunteers who have the virus, including 'pregnancy helpliners' who have given birth, are trained to counsel and advise.

* "Patients with genital herpes suffer considerable psychological morbidity and
the fact that they are able to receive very sophisticated and experienced
counselling ... has been extremely useful in helping them deal with their
condition. The HVA has fulfilled this role admirably over the years..."
Prof. M W Adler MD FRCP FFPHM, UCL Medical School, London
* "Nobody does what they do, filling an important niche."
Dr Paul Simmons MB FRCP, St Bartholomew's Hospital, London
helpline
$\mathbf{0 2 0} \mathbf{7 6 0 9} \mathbf{9 0 6 1}$
For leaflets, patient information cards or
posters, write or send e-mail to:
HVA, 41 North Road, London N79DP
We often hear this comment
"I wish I'd been told about you years ago"

\section{Visit the Faculty website at: www.ffprhc.org.uk}

